\title{
A self-sustaining community living environment for urban golden agers
}

\author{
H. Mohd Ali \& A. A. Ismail \\ Centre of Studies for Architecture, Faculty of Architecture, \\ Planning and Surveying, Universiti Teknologi MARA, Malaysia
}

\begin{abstract}
From a biological perspective, the ageing process is a gradual change in the physical ability of humans that occurs with the passage of time. The current census showed only a mere $5.1 \%$ of the overall population in Malaysia is over 65 years old. However, it is predicted that the ageing population will grow in the next 10 to 20 years due to an increasing awareness of better healthcare. However, most golden-agers will live isolated lives due to various personal reasons such as death of spouse, divorce, health problems, abandoned by their children, etc. A decline in physical articulations and slow response in intellectual skills are common. As their limitations conflict with the rapid development of modern technology, some golden-agers may find themselves drifting away from this modern world due to a dynamic cultural shift. Their everyday needs should not be taken lightly as they are different from the mass population. Thus, the objective of the research is to develop the idea of a retirement community where the urban golden-agers can live in a self-sustaining environment and independently with their peer group. The retirement community focuses on the design process that involves juxtaposed dwelling units, a partially assisted medical assistance facility and a community centre. Through precedent study, universal housing design and an innovative design approach, the research proposed mixed mode community living that addresses the needs of golden-aged citizens in physiological, mental and spiritual aspects. The retirement community aims to give the senior citizens a living environment that is holistic and relates back to the urban context.
\end{abstract}

Keywords: ageing process, design for urban golden-agers, self-sustaining, retirement community. 


\section{Introduction}

A retirement community is a housing complex with communal facilities designed for the retired community or older adults who are generally able to care for themselves. Medical assistance from the government or a private agency is provided for assisting residents and socialization opportunities are often provided. It would be excellent if the community were self-sustaining especially for golden agers that live in the urban areas. This would motivate them to be independent while living among their peers. Basically, one of the prerequisites to the community must be age and residents must be partially or fully retired. In Malaysia, the retirement age varies but it can be up to the age of 60 years old. The establishment of a retirement community in Malaysia must be incorporated with the local culture and institution. For instance, support from family members is encouraged as the establishment of a retirement community in Malaysia varies from the western setting. Regular visits and supervision from family members are encouraged to ensure that family ties remain close. The retirement community is a place which provides the basic needs of the elderly in terms of quality of space, facilities and other aspects.

\section{Present issues of golden agers}

The rising numbers of elderly population in Malaysia is not a small issue. From the census by the Department of Statistics Malaysia [1], the percentage of the elderly has doubled within a short duration. The figure will reach $15 \%$ of the total Malaysian population by the year 2030 and Malaysia can be declared as an "old country." The urbanization factor also leads to an imbalance in the demographic data. Young generations flock to the metropolitan area in search for better job opportunities and education leaving the parents unattended in the kampong or suburban areas. Thus, the establishment of retirement communities will help to monitor the well-being of the elderly without jeopardizing the responsibilities of children to visit and look after their parents. In Islam for instance, cutting the ties between families and negligence of parents' well-being is taboo. Therefore the provision of a retirement community is to help the elderly have a better quality of living and not be taken advantage of. The provision to put up the requirements of the elderly should be planned ahead. The execution of a universal design home should be implemented and integrated with the needs and requirements of the elderly. The retirement community aims to give a valuable experience to the senior citizens where it is not a mere place of living or just shade over their heads but holistically a place that holds sentimental values to the residents. Nothing is worth more than spending quality time with family and companions where there is always something to give back to the community and where life is valued most. Therefore, the retirement community is the definition of a better environment, lifestyle and barrier free living for the goldenagers. 


\subsection{Urbanization and migration factors}

Urbanization is an expansion or growth of the city centre because of migration factors. In this context, the migration of young generations to the metropolitan city such as Kuala Lumpur in search of better job opportunities and education will have an after effect on the local demographic data. According to the census by the Department of Statistics Malaysia [2], the Malaysian urbanization level is $71 \%$ compared to 1980 where the percentage is $34 \%$. The percentage is almost doubled from 1980 to 2010 and in terms of economic advancement in Malaysia is positively turning from an undeveloped third world country into a developing country. The outcome will inflict the imbalance of age group in the population; for instance, for the parents living in the suburban or kampong areas while their children are living in the urban or city centre areas. Moreover, the elderly population is rapidly increasing and thus the idea of the establishment of retirement community in Malaysia is valid. As they are aging, the need for a mixed residential typology responding to the elderly requirement is a must. Residential provision for the elderly will provide a daily life compliance with their needs and declining ability. Malaysian society nowadays begins to understand the importance of health and is beginning to plan their postretirement life. Records from the Department of Statistics in Malaysia in 2010 showed that life expectancy has increased from 71.6 to 71.9 years for male and 76.5 to 77.0 years for female supports this point of view.
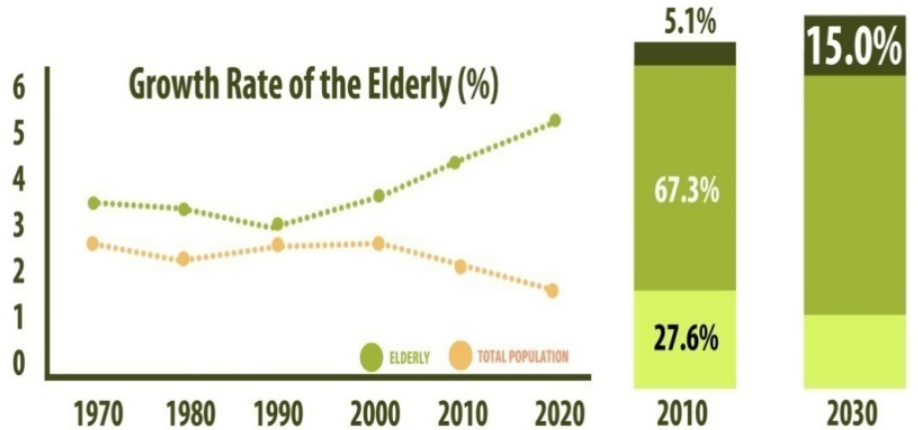

By the year $2030,15 \%$ of the population are 'ELDERLY'

Figure 1: $\quad$ Growth rates for the elderly and projected population of the elderly in 2030 (source: Department of Statistics, Malaysia [1].

\subsection{Growing elderly population}

The rising numbers of elderly in Malaysia is a natural process of the human cycle and quite a number of other countries face the same issue such as, notably, the United States, Japan and the United Kingdom. According to the census by the Department of Statistics in Malaysia in 2010, the percentage of the population over 65 years old is rising from $3.8 \%$ to $5.1 \%$ of a total 28 million Malaysians. As of right now, Malaysia is a relatively "young” and developing 
country but by the year 2030, $15 \%$ of the total population will consist of the elderly. Moreover, Malaysia will be officially an “old country” by the year 2050 . There are several factors leading to this problem such as the growth rate of the elderly being relatively higher than the percentage of the total population. The total fertility rate of Malaysian is also declining; from 2.9\% in the year 2000 to the rate of $2.5 \%$ in the year of 2010 [3]. These numbers will decrease at a steady pace if no solution or policy regarding improving the fertility rate is made.

\section{Precedent study: Devries Place Senior Apartment, Milpitas, California, USA [4]}

Built to be affordable, one of the goals is to have long term financial sustainability and viability. This award winning project is an exceptional design solution that combines historic preservation with affordability and, most importantly, sustainability. The fact that this development is linked into the existing neighborhood has proven to be vital especially for active living seniors. It is built next to existing civic resources such the public library and health centre for easy access.
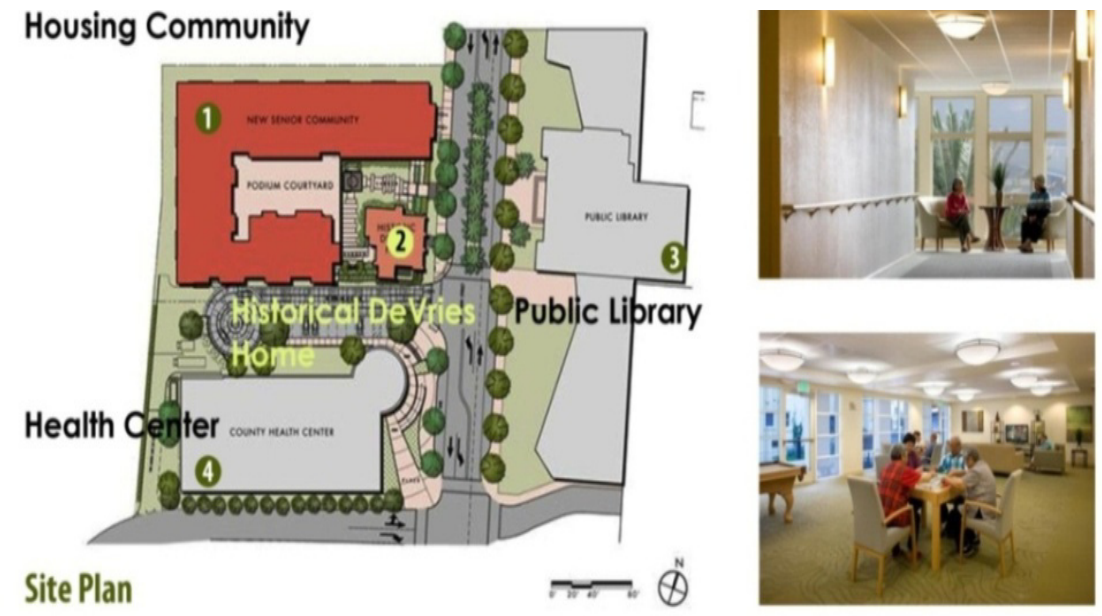

Figure 2: $\quad$ Site plan of Devries Place Senior Apartments (source: Design for Aging Review, 10 ${ }^{\text {th }}$ Edition (2011).

\subsection{Analysis of precedent study}

This retirement home highlights the importance of communal facilities to the elderly. It has centralized facilities on the podium level. The podium courtyard functions as the main public realm and not only beneficial in terms of green building but also a socialization area. Variation of communal activities provided 
such as gymnasium, theatre, communal kitchen, and laundry help the residents to create their own community within the facilities. Services, such as parking, are at the ground floor level in an effort to avoid conflict with the pedestrian route and "disappearing" from the main view.

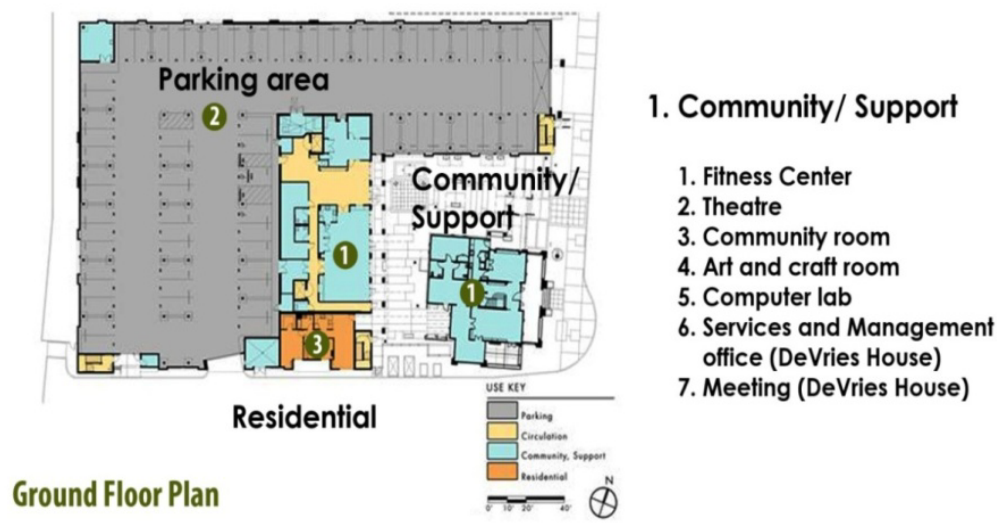

Figure 3: $\quad$ Ground floor plan of Devries Place Senior Apartments (source: Design for Aging Review, $10^{\text {th }}$ Edition (2011).

For green features, the architect has designed an efficient roof form with photovoltaic panels and a rooftop terrace. The residential unit is also equipped with a clever shading device to minimize heat gain and glare in the interior space. With masterful thought and consideration, nobody can realize that this is an affordable retirement home.

\section{Establishing a self-sustaining community for urban golden-agers}

There are several guiding criteria that help to improve the retirement community in order to give maximum benefits to the residents. The requirements are vital to ensure the success of it. The needs for a self-sustaining retirement community are evident as the benefits of retirement community outweigh its weaknesses. It is the solution for the issues raised earlier. The criteria of establishing a dynamic and self-sustaining retirement community are as follows:

i. To provide community based facilities;

ii. To create a home-like environment;

iii. To connect to the existing neighbourhood and immediate urban context;

iv. Permaculture as an activity of daily living;

v. To allow for the residents to age-in-place with a holistic approach to wellness. 


\subsection{Providing community based facilities}

First and foremost, it is about creating a community within the facility. By promoting residents a sense of community, they feel more secure and the chances of socialization are higher; for instance, providing common spaces that encourage socialization among the residents such as a game room, dining room or even an outdoor area such as a courtyard. Courtyard design is essential in a retirement community because it gives such benefits to the residents. It is one of the intimate features because courtyard design provides security and a sense of ownership to the residents. Besides that, circulation can also be part of the socialization opportunity; for instance by dividing the residential unit into smaller clusters, it helps to know the neighbors better. Facilities play an important role in embracing and bringing the people together so it will become a community. Socialization is vital among the elderly as they are aging and becoming more sensitive behavior-wise. Thus, the facilities indirectly will maintain the physical and spiritual well-being of the residents.
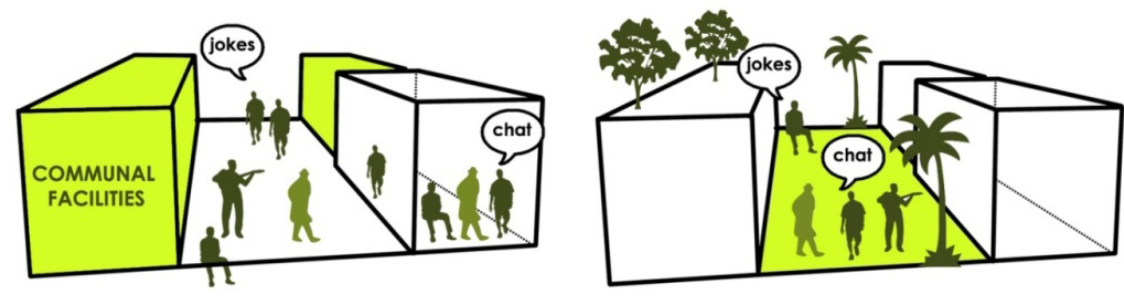

Figure 4: $\quad$ Promoting socializing among residents (source: authors (2013).)

\subsection{Creating a home-like environment}

Secondly, to provide a home-like environment for the residents; the AIA [4] clarified the important criteria in presenting a home-like environment such as a welcoming entrance, creation of neighborhoods, and incorporating residential design elements. By creating a cluster of neighborhood, it allows for more communication and activities among the residents. On top of that, proper supervision and visits from family members or children also should be encouraged. The retirement community is a housing typology designed to accommodate the needs of the elderly. Adding on some residential design elements such as a balcony and private kitchen will give the residents a sense of ownership and privacy. Access to the views of nature is an additional benefit as it will give more value to the residents. By adding modulating long corridors and interplaying with green pockets also makes it look less institutional.

\subsection{Connecting to the existing neighborhood}

The third element to ensure the triumph of a retirement home is to consider its existing neighborhood and relation to its surrounding. It is one of the 
fundamental considerations in architectural practice to allow the building to naturally fit within the site context. For example, if the site is related within a historical site, it is sensible to preserve or adaptively re-use existing historic features or buildings. The same principle applies in natural heritage or preserved land by having a sensitive design in order to avoid any imbalance or upset in the ecosystem. The siting of the building or complex also should be respectful to the neighbors and incorporating with the local climate such as building orientation, wind direction, views, natural ventilation, etc. Aside from respect towards the natural elements, the architect should also do the same on the local socio-cultural aspect; for instance, having the architectural language of the building reflect the surroundings in terms of form, colors and materials.

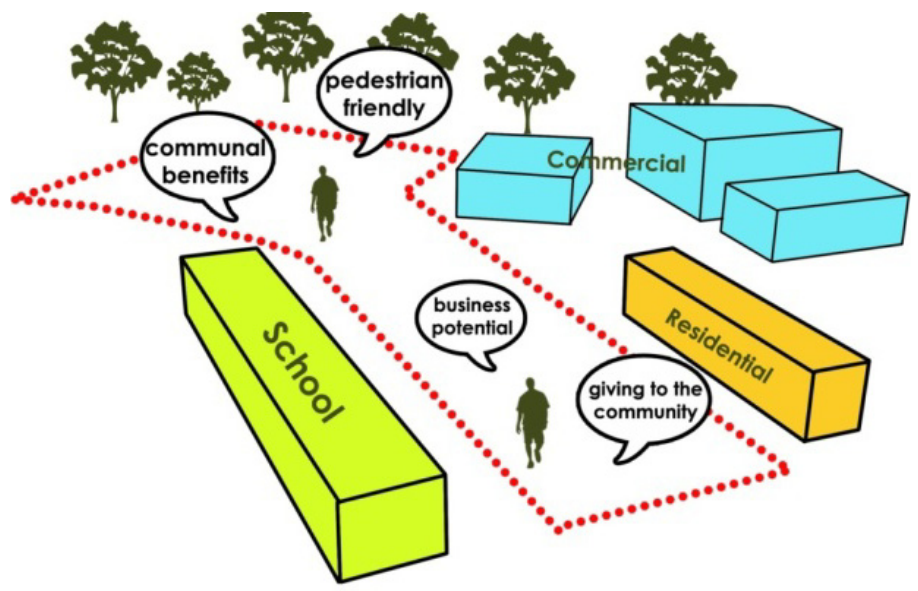

Figure 5: Connecting to the existing neighborhood (source: authors).

\subsection{Permaculture as an activity of daily living}

The fourth component is providing activities that are suitable for the residents. Most of the retirement homes offer a variety of activities to choose from. The classification of the facilities may be range from physical activities, interactive or simply hobbies. The courtyard for instance, can be adapted into a therapeutic or edible garden. Thus the courtyard will not be merely a place for interaction but also a place for communal activities such as permaculture. Permaculture is a technique that can be used to design human settlements and agricultural systems mimicking those in natural ecologies [6]. It can be practiced in urban areas and is essentially common sense living, which means using the resources available to the fullest. These include intensive small scale gardening, recycling and container planting. Malaysians are renowned to be very close with nature since 
almost every household has their own garden or potted plants for those who do not have land or ground. The permaculture activity can be included in the activity of daily living (ADL) for the residents to promote a healthy lifestyle. It is not only beneficial for the body, but also for the mind and soul. Permaculture can be utilized as an alternative therapy method with the least cost while the residents can reap the benefits.

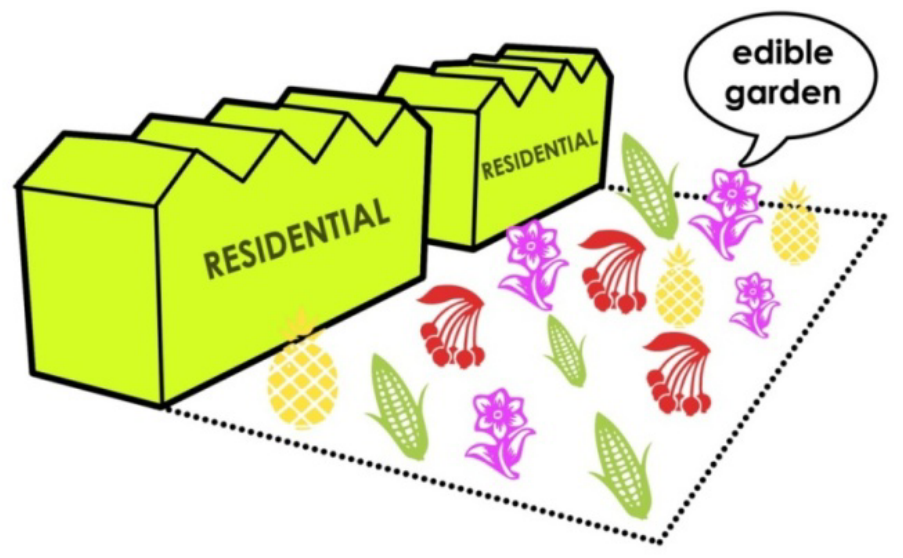

Figure 6: $\quad$ Permaculture as an activity for daily living (source: authors).

\subsection{Allowing residents to age-in-place and with a holistic approach to wellness}

The fifth component is to allow residents to age-in-place. This component caters for the more complex or more target users such as independent living, assisted living or skilled nursing facilities. Medical assistance is often provided to ensure that the health of the residents is looked after. Apart from medical assistance, the aging-in-place attribute can be incorporated in architectural design such as universal design features in residential areas and accessibility to encourage independence, including easy access to outdoor spaces and communal facilities such as lean rails in the corridors. Moreover, the building complex should be near or integrated to reduce walking distance and introducing a pedestrianoriented development to reduce vehicular dependency. A retirement home that proposes a variety of communal activities is proven to be more significant than the others. Physical wellness is simply advocating healthy lifestyle habits, encouraging personal safety and the appropriate use of the healthcare system. Social wellness is to maintain healthy relationships by talking, sharing interests or hobbies and participating in communal events. Intellectual wellness is to encourage individuals to expand their knowledge and skill through a variety of resources and cultural activities. Emotional wellness is the capacity to manage 
feelings and behaviors, while the spiritual wellness is seeking meaning and purpose.

\section{Conclusion}

The proposed self-sustaining retirement community is somewhat a typology where it juxtaposes the dwelling unit with a medical assistance unit and other facilities. It emphasizes more on the way of living and thus the communal facilities play a vital role to ensure the success of a retirement community. The retirement community should also help residents bond with the users' spiritual needs. Merging these values into the local setting of local customs and oriental etiquette, the retirement community should also consider that spiritual values should be incorporated into the building. For instance, a religious person usually needs a place to fulfill his or her spiritual needs. The "search" for peace and tranquility is the main ambition for a man before meeting his or her Creator. A self-sustaining retirement community is the definition to a better environment, lifestyle and barrier free living for the golden-aged citizen. Many of them normally encounter physical barriers and limitations in conventional dwelling units and it is vital for the retirement community to cater and minimize these matters as much as possible. It is essential to embrace the condition that being elderly is a privilege and not be against it as argued by de Vries [5] in an unconventional manner in the following excerpt:

We dare not forget that aging comes not when we pass a certain birthday but when the regrets take the place of dreams, when we desert our ideals. Worry, doubt, self-interest, and despair are the furies that destroy a person's spirit. We need to go beyond Benjamin Disraeli's lament that "youth is a blunder; manhood is a struggle; old age, a regret."

\section{References}

[1] Department of Statistics, Malaysia. (2010). Population Distribution and Basic Demographic Characteristic Report 2010. Accessed May $6^{\text {th }}, 2012$ $<$ http://www.statistics.gov.my>

[2] Department of Statistics, Malaysia. (2011). Statistics Handbook Malaysia. Putrajaya, Malaysia.

[3] Department of Social Welfare, Malaysia. (2011). Accessed October $12^{\text {th }}$, 2012 http://www.jkm.gov.my

[4] The American Institute of Architects (AIA). (2011). Design for Aging Review, $10^{\text {th }}$ Edition Victoria 3170, Australia: Images Publisher.

[5] de Vries, M. K. (2003). The Retirement Syndrome: The Psychology of Letting Go. Leadership Development, INSEAD.

[6] Millen, T. (2006). Greening the Planet, One Backyard at a Time. In Ecos, issue Aug-Sept 2006, 132, pp. 30-31. CSIRO Publishing. 